\title{
Automatic Forest Fire Detection and Suppression Smart Grid System
}

\author{
Gopalakrishnan G1, Arul Mozhi Varman S', Dinessh T C ${ }^{1}$, Divayarupa $\mathrm{S}^{1}$, Benazir Begam $\mathrm{R}^{2}$ \\ ${ }^{1}$ U.G Scholar, Department of Electronics and Communication Engineering, Rajalakshmi Engineering College, \\ Chennai, Tamil Nadu, India \\ ${ }^{2}$ Assistant Professor, Department of Electronics and Communication Engineering, Rajalakshmi Engineering \\ College, Chennai, Tamil Nadu, India
}

\begin{abstract}
Article Info

Volume 8, Issue 3

Page Number : 666-669

Publication Issue

May-June-2021

\section{Article History}

Accepted : 10 June 2021

Published : 17 June 2021

Over the past years, a radical change in Earth's temperature has been recorded. It has caused global warming and severe changes in climatic conditions. Naturally, this has resulted in many natural disasters. Forest fire is one such calamity that harms the environment to a great extent. The traditional methods of controlling and suppressing the fires are ineffective as the fires spread too rapidly if it is not contained at the initial stage. Hence this paper proposes a system that aims to automatically detect forest fires and suppress them. This system will suppress and contain the forest fires long enough for the firefighters to arrive.

Keywords: Forest fire, Detection, suppression, Sensor network.
\end{abstract}

\section{INTRODUCTION}

Forest fires are one of the major natural calamities that threaten the balance of life on Earth. Forest fires or wildfires are caused by both natural causes and man-made causes. Natural causes include lightning, volcano, etc. Due to the dry weather, the forest floor becomes littered with dry leaves and twigs. These serve as the fuel for the fire. Man-made causes of the fires are Cigarette butts, campfires, and electric sparks. Around eighty percent of the forest fires are due to human carelessness. The effect of forest fires on biodiversity is dire. They affect both flora and fauna. Many species of animals have become endangered due to these wildfires. Humans also suffer due to these fires. There is a loss of livelihood for the native people and the smoke from the fires causes diseases to people.

Traditional methods of forest fire detection are to use satellite imaging and drone monitoring. Manual patrolling is also done. But even if the fire is detected, it takes approximately around twenty minutes for the alert to reach the base and for the rescue team to be dispatched to fight the fire. The fire will envelop a vast area before the firefighters arrive. If the fire becomes too large, it becomes very difficult to suppress it. 


\section{CASE STUDY : AUSTRALIAN BUSH FIRE 2019}

The Australian bush fire started in September 2019 and has been raging on ever since. This is the most devastating disaster that Australia has ever encountered. Though the country experiences bushfires normally every year, the bushfire of the year 2019 has proven to be the worst ever on record. The main reason was found to be the heavy droughts and global warming. The winds also favored the swift spread of the fire. The most affected states were New South Wales and Victoria on the southeast coastline. In New South Wales more than five million hectares have been destroyed and in Victoria, around 1.2 million hectares have been damaged [1].

Australia is considered to be a hotspot for biodiversity being the home for many exotic species. Scientists have estimated that around a billion animals have perished to the fires including many endangered species. The Kangaroo Island known for its unique mix of animal species was also affected and it is been estimated that around 25,000 koalas were killed in the fire. There is a real fear that the lost species may not be recovered ever. Around 3000 people have lost their homes and around 35 people were killed including 4 firefighters. The air pollution caused by the fires has reduced the quality of air and introduced new diseases.

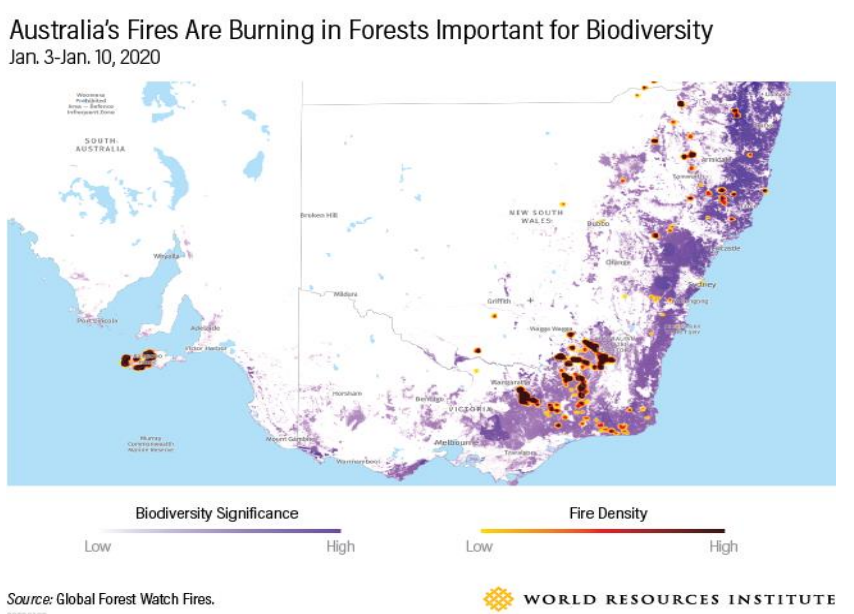

FIG.1 AUSTRALIAN BUSH FIRE STATISTICS

\section{LITERATURE REVIEW}

There is much research being conducted to try to minimize the effects of forest fires [2] [3]. Fire detection using spatial and video data is presented in the paper "Speculation of Forest Fire Using Spatial and Video Data" sone by Divya TL [4]. In this technique, the fires are detected using videos. It uses spatiotemporal features to analyze fire movements in the videos. This system is based on video processing.

Another common technique is to use the wireless sensor network [5]. Wireless sensor networks are implemented to collect the data such as temperature, humidity, and other such data in real-time and send them to distant storage [6]. Any signs of fire are detected and sent to the database and the officials get an alert.

\section{METHODOLOGY}

\section{A) ARCHITECTURE}

A wireless sensor network is created with smart nodes that can detect and suppress the fire. The nodes detect the environment parameters to detect the fires. The base node will be connected to the internet to connect to the cloud. A mesh topology of the network is used. The nodes will be able to communicate between them and the data transfer is continued until it reaches the base node where it will be uploaded to the cloud. The nRF24L01 transceiver is used for nodeto-node communication purposes. It uses $2.4 \mathrm{GHz}$ ISM frequency and uses the GFSK modulation technique for data transmission. The range of this transceiver is around $1000 \mathrm{~m}$. The nRF24L01 uses only 5V for its operation. The nodes are spaced sufficiently at a distance of five hundred meters. NodeMCU microcontroller is used in the base node to connect to the internet.

\section{B) DETECTING THE FIRE}

Fire detection is done using the Infrared Flame Sensor. Every burning fire emits electromagnetic waves in the infrared range. These waves have wavelengths in the range of $760-1100 \mathrm{~nm}$. The infrared flame sensor 
senses the infrared waves from the fires to detect the break out of the fire. A single node is fitted with two flame sensors each covering 180 degrees. A servo motor is used to rotate the sensors about 180 degrees on each side. Further, the DHT11 sensor is used to measure the temperature and humidity to predetermine forest fires. The environmental temperature is a main factor for the fires. It is during the dry season when the temperature is high and the humidity is low, the forest fires happen. Using the temperature and the humidity sensor it is possible to prevent the fires before it starts. The collected data is then processed by the nodeMCU microcontroller and then it is transmitted using the nRF24L01 transceiver to the base node.

\section{C) SUPPRESSING THE FIRE}

Each node is provided with a water pump. The node is made to be hollow to store water inside it. When the flame sensor detects a fire, the water pump is turned on. Water is sprayed via a nozzle with the help of the pump. The nozzle is also turned around 180 degrees using a servo motor to cover a wider area. The water needed for the suppression is collected through rainwater harvesting. The node is equipped with a hatch on the top. The hatch is opened when it rains and the water is collected in it. Manual filling of water can also be done in case of insufficient rain.

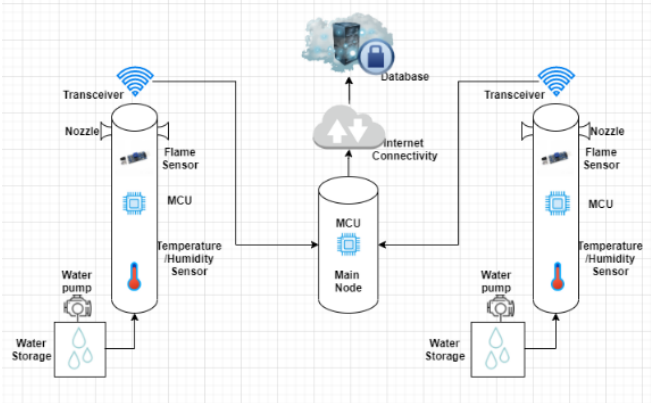

FIG.2 BLOCK DIAGRAM OF SYSTEM

\section{D) BLOCK DIAGRAM}

The main challenge in a wireless sensor network is the power module. The battery should provide enough power for the sensor modules and the network modules. Solar rechargeable lithium batteries will have a long lifespan of about twenty years and provide sufficient power.

\section{E) WEBSITE}

The sensor data is then sent to the firebase real-time database by the nodeMCU microcontroller. A website is provided showing the status of each data. The website can be used by people to know if there is any break out of forest fires. The website also has an admin mode. Admins can control the nodes manually such as turning on the water pump. A map is also shown displaying the location of each node.

\section{RESULTS}

The prototype of the network node was built and tested. The flame sensor was able to detect the test fire and the values were updated in the firebase database. The fire was automatically suppressed immediately with the help of the water pump.

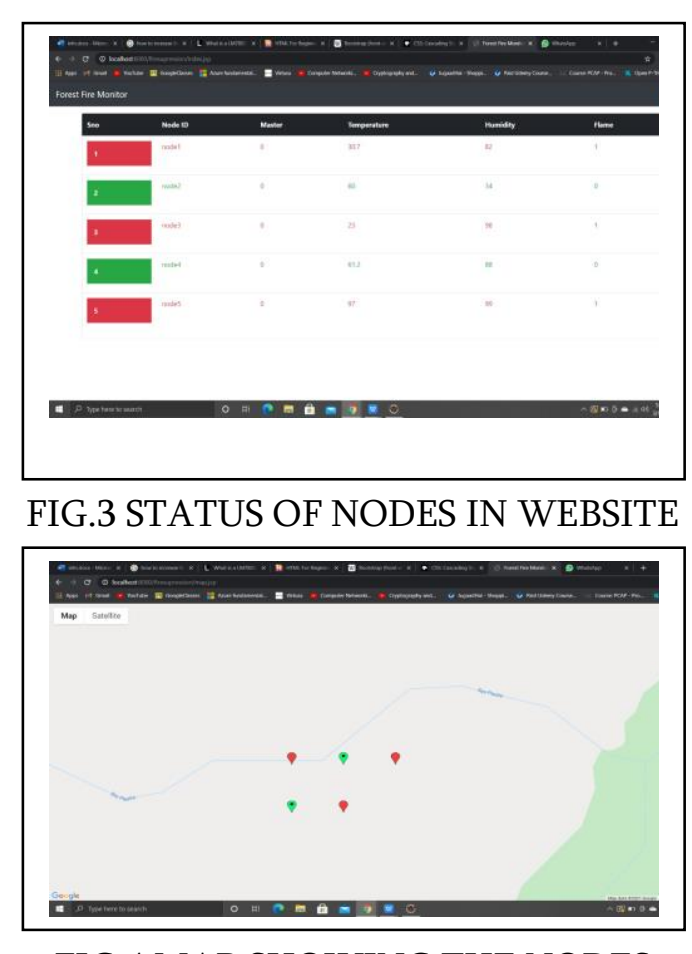

FIG.4 MAP SHOWING THE NODES 


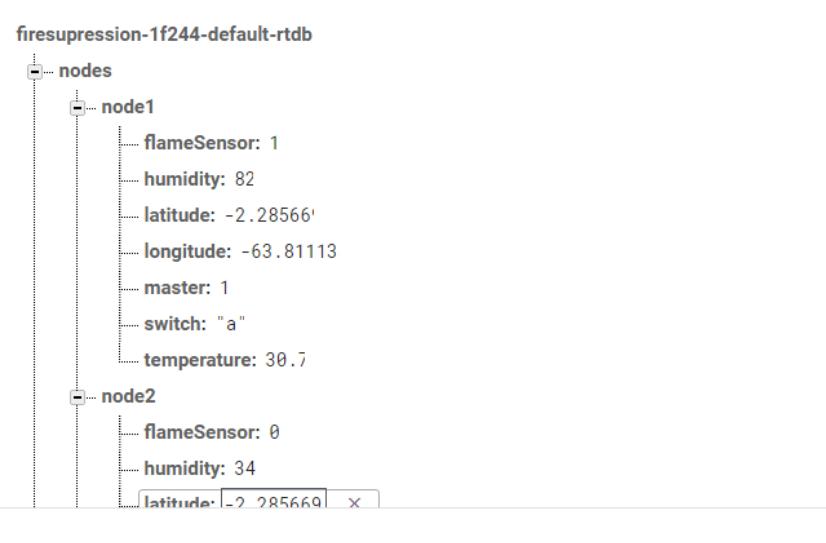

FIG.5 FIREBASE DATABASE

\section{CONCLUSION}

Forest fires are a very major threat to planet Earth. A county's economy is also affected by the destruction caused by the wildfires along with the irrevocable loss of biodiversity. By implementing the proposed system, forest fires can be detected and suppressed easily. The system is easy to implement and is cost-effective.

\section{REFERENCES}

[1]. "BBC," 13 January 2020. [Online]. Available: https://www.bbc.com/news/world-australia50951043.

[2]. Z. Yingli, X. Lingqin and Y. Tingting, "Monitoring System for Forest Fire Based on Wireless," Proceedings of the 10th World Congress on Intelligent Control and Automation, no. 6, 2012.

[3]. H. Dang-Ngoc and H. Nguyen-Trung, "Aerial Forest Fire Surveillance - Evaluation of Forest Fire Detection Model using Aerial Videos," in 2019 International Conference on Advanced Technologies for Communications (ATC), 2019.

[4]. T. Divya, M. Vijayalakshmi and S. Anupama Kumar, "Speculation of Forest Fire Using Spatial and Video Data," in 2019 1st International Conference on Advanced Technologies in Intelligent Control, Environment, Computing
\& Communication Engineering (ICATIECE), 2019.

[5]. G. Demin, L. Haifeng, J. Anna and W. Guoxin, "A forest fire prediction system based on rechargeable wireless sensor networks," in 2014 4th IEEE International Conference on Network Infrastructure and Digital Content, 2014.

[6]. L. Guang-Hui, Z. Jun and W. Zhi, "Research on Forest Fire Detection Based on Wireless Sensor Network," in 2006 6th World Congress on Intelligent Control and Automation, 2006.

\section{Cite this article as :}

Gopalakrishnan G, Arul Mozhi Varman S, Dinessh T C, Divayarupa S, Benazir Begam R, " Automatic Forest Fire Detection and Suppression Smart Grid System", International Journal of Scientific Research in Science and Technology(IJSRST), Print ISSN : 2395-6011, Online ISSN : 2395-602X, Volume 8, Issue 3, pp.

666-669, May-June-2021. Available at doi $\quad$ : https://doi.org/10.32628/IJSRST2183158

Journal URL : https://ijsrst.com/IJSRST2183158 